\title{
Long Length Fabrication of YBCO on Rolling Assisted Biaxially Textured Substrates (RABiTS) using Pulsed Laser Deposition
}

\author{
C. Park, D. P. Norton, D. K. Christen, D. T. Verebelyi, R. Feenstra, J. D. Budai \\ Solid State Division, Oak Ridge National Laboratory, Oak Ridge, TN 37831-6056 \\ A. Goyal, D. F. Lee, E. D. Specht, D. M. Kroeger \\ Metals and Ceramics Division, Oak Ridge National Laboratory, Oak Ridge, TN 37831-6116
}

M. Paranthaman

Chemical and Analytical Sciences Division, Oak Ridge National Laboratory, Oak Ridge, TN 37831-6100

\begin{abstract}
The continuous deposition of multilayer oxide films on moving long-length metallic substrates using pulsed laser deposition (PLD) is reported. Epitaxial $\mathrm{YBCO} / \mathrm{CeO}_{2} / y$ ttria-stabilized zirconia (YSZ)/ $\mathrm{CeO}_{2}$ layers were grown on $1 \mathrm{~cm} \mathrm{X}$ $10 \mathrm{~cm}$ rolled-Ni tape substrates. The Ni tape was heated radiatively and translated while oxide layers were continuously deposited. The thickness and composition along the moving direction were uniform to within $\pm 7 \%$ and $\pm 5 \%$, respectively. The biaxial texture of the $10 \mathrm{~cm} \mathrm{Ni}$ tape was transferred through the buffer layers to the topmost YBCO during the continuous deposition. The in-plane and out-of-plane texturing of YBCO and buffer layers were uniform along the scanning direction with variations less than $\pm 10 \%$ and $\pm 5 \%$, respectively. The average transport zero field $J_{c}$ (77K) for numerous $10 \mathrm{~cm}$ samples was about $200,000 \mathrm{~A} / \mathrm{cm}^{2}$, with the highest $J_{c}$ and $I_{c}$ values at $77 \mathrm{~K}$, $0 \mathrm{~T}$ of $270,000 \mathrm{~A} / \mathrm{cm}^{2}$ and $16.7 \mathrm{~A}$ respectively. This study demonstrates the feasibility of continuous multilayer, multi-component oxide film deposition on rolled-textured metal with uniform thickness, composition, and crystallographic orientation using PLD.
\end{abstract}

\section{INTRODUCTION}

The second generation superconducting wire technology which is typified by the $\mathrm{YBa}_{2} \mathrm{Cu}_{3} \mathrm{O}_{7-\mathrm{x}}$ (YBCO) coated conductor, is regarded as a promising approach for high temperature superconductor (HTS) power applications at liquid nitrogen temperatures, and is a topic of significant activity in the field of high temperature superconductivity. The Rolling Assisted Biaxially Textured Substrate (RABiTS) process, which is one approach to obtaining YBCO coated conductor, utilizes a biaxially textured metal tape, formed by cold-rolling and annealing, as the initial textured substrate. YBCO films possessing zero field critical current density $\left(\mathrm{J}_{\mathrm{c}}\right)$ and in-field properties comparable to those deposited on single crystal substrates have been successfully synthesized on the

Manuscript received September 14, 1998.

This research was sponsored by the Oak Ridge National Laboratory, managed by Lockheed Martin Energy Research Corp., for the U.S. Department of Energy, under contract DE-AC05-960R22464. rolled-textured $\mathrm{Ni}$ substrates with multi-layer oxide buffer layers. The details have been reported elsewhere [1]-[4].

Most of the effort reported to date has focused on the fabrication of the YBCO/buffer layer architecture on small rolled-Ni substrates (less than $5 \mathrm{~mm}$ X $20 \mathrm{~mm}$ ) for RABiTS process development. In order to further evaluate the RABiTS approach, long-length conductor synthesis will need to be demonstrated. There have been many efforts to deposit high quality YBCO films on large area substrates using pulsed laser [5]-[16]. In most cases, the focus has been on preparing YBCO films on large (up to 3 inches in diameter) $\mathrm{Si}, \mathrm{MgO}$, $\mathrm{NdGaO}_{3}, \mathrm{LaAlO}_{3}$, or sapphire single crystals for microwave and digital electronic device applications. Many ingenious ideas regarding the laser beam rastering, target manipulating, and/or substrate heating/rotating made possible a good deal of advancement in this area. For instance, the deposition of YBCO films with excellent superconducting and structural properties on substrates the size of $7 \mathrm{~cm} \mathrm{X} 20 \mathrm{~cm}$ with thickness variation of less than $\pm 9 \%$ has been demonstrated with pulsed laser deposition (PLD) [6], [7].

In this paper, we report on the continuous deposition of multilayer $\mathrm{YBCO} / \mathrm{CeO}_{2} / \mathrm{yttria}$-stabilized-zirconia (YSZ) $/ \mathrm{CeO}_{2}$ oxide films on $1 \mathrm{~cm} \mathrm{X} 10 \mathrm{~cm}$ rolled-Ni tape using PLD.

\section{EXPERIMENTAL SETUP AND PROCEDURE}

The Ni tape was radiatively heated and linearly translated in the direction perpendicular to that of the plume. Fig. 1 shows schematically the PLD system used in this study. The incident laser radiation $(248 \mathrm{~nm})$ reflects off a rotating mirror, passes through two focusing lenses and a quartz window, and impinges onto $50 \mathrm{~mm}$ diameter rotating targets with an angle of incidence of $\sim 45^{\circ}$. The focused laser beam is rastered over the target elliptically ((1) in Fig. 1(b)) using the rotating mirror in which the axis of rotation is asymmetrically off the laser beam direction. In addition to rotating ((2) in Fig. 1(b)), the target is also moving back and forth between two offcenter positions ((3) in Fig. 1(b)) after a set number of laser pulses, so that the center of the laser beam ellipse is off the center of the target. The left and right (in Fig. 1(b)) sides of the target are eroded by the laser beam equally, thus minimizing the evolution of undesirable target texturing. 


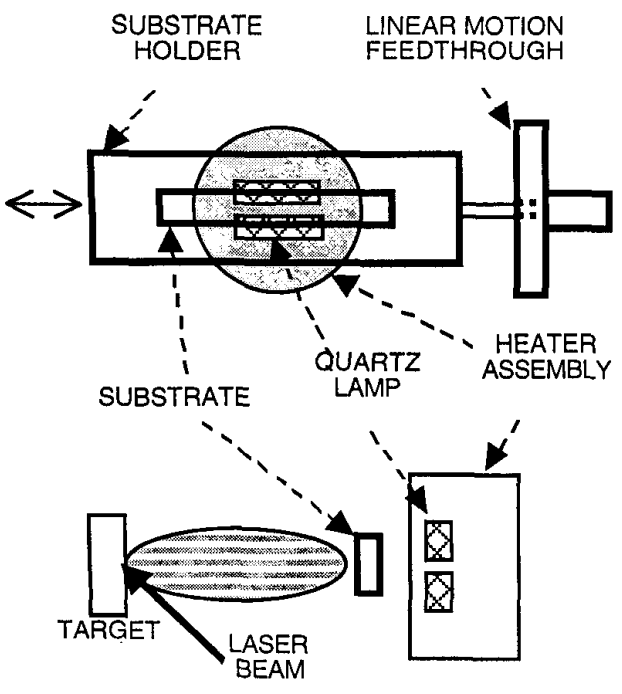

(a)

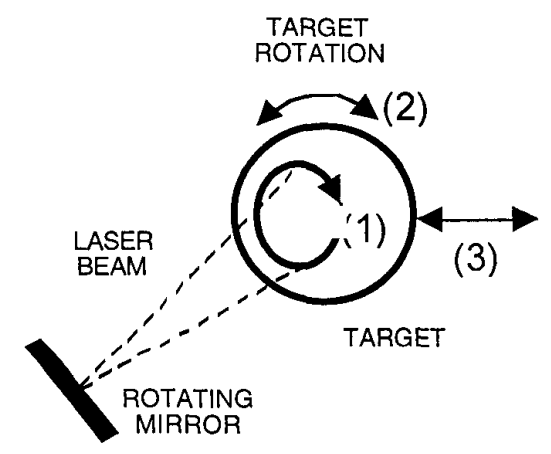

(b)

Fig. 1. Schematic of (a) PLD system and (b) beam rastering / target manipulating scheme.

More than $80 \%$ of the target surface is utilized with this beam rastering / target manipulation scheme.

The substrate was radiatively heated by two quartz halogen lamps, each with a power of 500W. To avoid deposition on the part of the substrate that is not in the appropriate temperature range and which is exposed to the outer edge of the plume, a plate with an aperture of $20 \mathrm{~mm}$ in the direction of the substrate movement was inserted between the target and the substrate. The substrate $(1 \mathrm{~cm} \mathrm{X} 10 \mathrm{~cm})$ was attached to a holder, one end of which was connected to the linear motion feedthrough. The target-to-substrate and substrate-to-heater distances were $7 \mathrm{~cm}$ and $\sim 1 \mathrm{~cm}$, respectively.

The measurement and control of the substrate temperature is a significant challenge during radiative heating of the moving tape. A thermocouple (T/C) spot-welded to a piece of Hastelloy foil was placed between the substrate and the quartz lamp in such a way so as not to perturb the temperature distribution of the substrate. The signal from this $\mathrm{T} / \mathrm{C}$ was used to provide temperature feedback to the substrate temperature controller. The actual substrate temperature was estimated using a calibration curve obtained by using another $\mathrm{T} / \mathrm{C}$ attached directly onto the surface of a $\mathrm{Ni}$ substrate. The calibration curve was obtained for the four different deposition conditions - (1) $180 \mathrm{mTorr} 4 \% \mathrm{H}_{2} / \mathrm{Ar}$ for $\mathrm{CeO}_{2}$, (2) vacuum (5 X $10^{-6}$ Torr) for $\mathrm{CeO}_{2}$, (3) $10^{-4}$ Torr $\mathrm{O}_{2}$ for $\mathrm{CeO}_{2}$ and YSZ, and (4) $200 \mathrm{mTorr}^{\mathrm{O}_{2}}$ for $\mathrm{YBCO}$. Deposition temperatures used were $700-725^{\circ} \mathrm{C}$ for $\mathrm{CeO}_{2}$ and $\mathrm{YSZ}$, and $750-785^{\circ} \mathrm{C}$ for YBCO.

The substrate holder was designed to maintain constant tension on the $\mathrm{Ni}$ tape in order to prevent bending due to thermal expansion. Typical deposition conditions for the films include a fluence of $1.5 \mathrm{~J} / \mathrm{cm}^{2}$, with a laser repetition rate of 3 to $10 \mathrm{~Hz}$. The substrate was translated at speeds ranging from 2.3 to $9 \mathrm{~mm} /$ minute. Multiple scans of the substrate through the deposition chamber were made to deposit each layer.

\section{RESULTS AND DISCUSSION}

Fig. 2 shows the temperature profile of the substrate obtained from a calibration run performed in $180 \mathrm{mTorr} 4 \%$ $\mathrm{H}_{2} / \mathrm{Ar}$. This curve was obtained by moving a $\mathrm{Ni}$ tape (with calibration T/C attached on the surface facing the target) at a speed of $7 \mathrm{~mm} /$ minute while the temperature of the heater assembly was kept constant. The temperature distribution did not show any dependence on scanning speed up to 9 $\mathrm{mm} /$ minute. There was a $25^{\circ} \mathrm{C}$ difference in temperature in the section of $\mathrm{Ni}$ that is exposed to the plume through the aperture of size $20 \mathrm{~mm}$ in the scanning direction. This difference in temperature in the $20 \mathrm{~mm}$ section increased to about $30^{\circ} \mathrm{C}$ for the conditions used to deposit YBCO film.

The thickness profile of a YBCO film (average thickness of $1.1 \mu \mathrm{m}$ ) deposited on a $1 \mathrm{~cm} \mathrm{X} 10 \mathrm{~cm} \mathrm{Ni} \mathrm{substrate} \mathrm{in} \mathrm{the}$ direction of the scanning is shown in Fig. 3. The thickness variation, as measured by the stylus profilometer, was $\pm 7 \%$. It took 130 minutes $(10 \mathrm{~Hz}$ laser pulse, scanning speed 2.3 $\mathrm{mm} /$ minute) to deposit the YBCO film shown in Fig. 3. The good thickness uniformity indicates that the intensity of the plume was kept nearly constant throughout the YBCO deposition, reflecting the utility of beam rastering and target

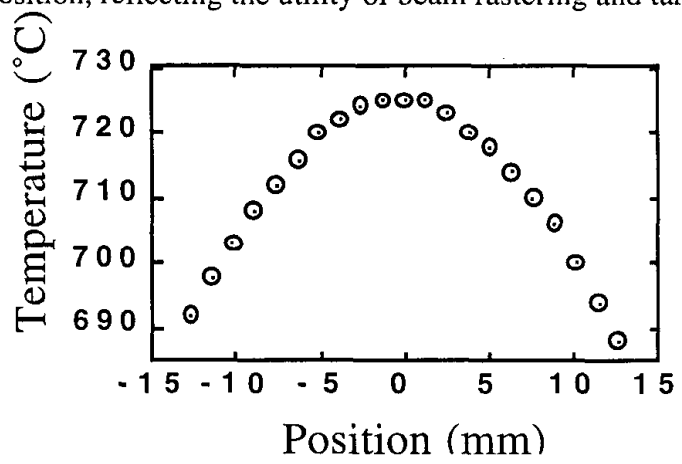

Fig. 2. Temperature profile of the $\mathrm{Ni}$ substrate parallel to the scanning direction. 


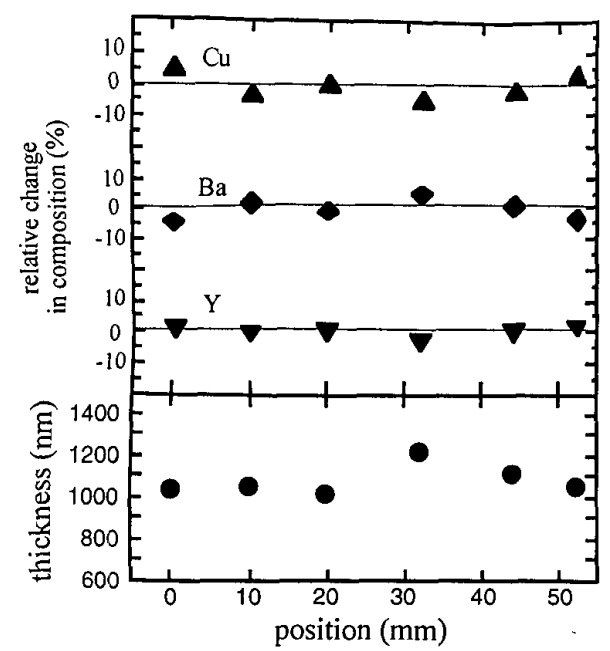

Fig. 3. Relative $\%$ change in composition and the variation of thickness of YBCO film obtained over central $5 \mathrm{~cm}$ section of $1 \mathrm{~cm} \mathrm{X} 10 \mathrm{~cm} \mathrm{Ni}$ substrate along the substrate scanning direction.

manipulation. The YBCO film deposition rate was approximately $30 \mathrm{~nm} /$ minute in the $20 \mathrm{~mm}$ (aperture opening size) $X 10 \mathrm{~mm}$ (width of the tape) area.

Fig. 3 also shows the composition profile of the same region for this film. Energy dispersive X-ray spectrometry was used to determine relative amounts of composition change in $\mathrm{YBCO}$ film. The concentrations of $\mathrm{Y}, \mathrm{Ba}$, and $\mathrm{Cu}$ were uniform to within $\pm 3 \%, \pm 4 \%$, and $\pm 5 \%$, respectively.

Fig. 4 (a) shows the XRD results from $\phi$-scans of a $\mathrm{YBCO} / \mathrm{CeO}_{2} / \mathrm{YSZ} / \mathrm{CeO}_{2} /$ rolled-Ni structure. The in-plane FWHMs obtained from YBCO (113), YSZ (111), $\mathrm{CeO}_{2}$ (111) and $\mathrm{Ni}$ (111) peaks were $12.6^{\circ}, 11.6^{\circ}, 10.1^{\circ}$, and $10.9^{\circ}$ respectively. This indicates that the biaxial texture of the long length, moving $\mathrm{Ni}$ tape was transferred through the buffer layers to the $\mathrm{YBCO}$ as was previously shown for films deposited on small area, stationary $\mathrm{Ni}$ substrates [1]-[4]. The variation of in-plane and out-of-plane orientations of YBCO and YSZ layers along the substrate scanning direction in the central $15 \mathrm{~mm}$ region is shown in Fig. 4 (b). The in-plane and out-of-plane texturing of $\mathrm{YBCO}$ and buffer layers are uniform along the scanning direction with variation less than $\pm 10 \%$ and $\pm 5 \%$, respectively.

The superconducting transition temperatures of the films were in the range $86 \sim 89^{\circ} \mathrm{C}$. The average transport zero field $\mathrm{J}_{\mathrm{c}}$ (77K) measured by the standard four-probe method using a 1 $\mu \mathrm{V} / \mathrm{cm}$ criterion was $-200,000 \mathrm{~A} / \mathrm{cm}^{2}$. The highest $J_{c}$ and $I_{c}$ at $77 \mathrm{~K}$, 0T obtained was $270,000 \mathrm{~A} / \mathrm{cm}^{2}$ and $16.7 \mathrm{~A}$, respectively when the voltage drop was measured between two voltage taps $1 \mathrm{~cm}$ apart.

\section{SUMMARY}

The continuous deposition of multi-layer oxide films on 10 $\mathrm{cm}$-long rolled-textured $\mathrm{Ni}$ substrates was demonstrated using

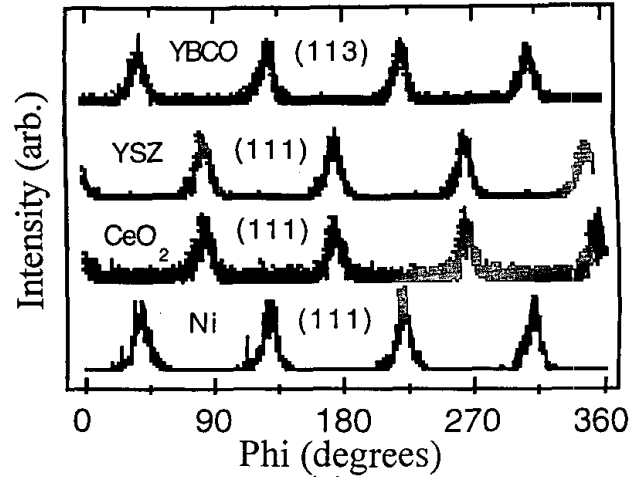

(a)

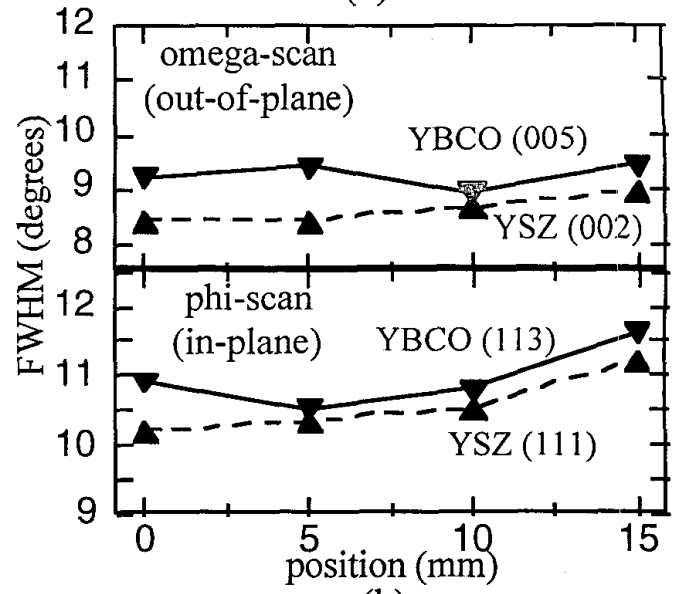

(b)

Fig. 4. (a) XRD results from $\phi$-scans of $\mathrm{YBCO} / \mathrm{CeO}_{2} / \mathrm{YSZ}_{\mathrm{CeO}} / \mathrm{Ni}$, and (b) the variation of in-plane and out-of-plane orientation of YBCO and YS? along the scanning direction.

PLD. The Ni tape was heated radiatively and translated while oxide layers were continuously deposited. Good uniformity of the film thickness, composition, and texturing along the substrate moving direction was observed. An average zero field $J_{c}(77 \mathrm{~K})$ of approximately $200,000 \mathrm{~A} / \mathrm{cm}^{2}$ was achieved, with the highest $J_{c}$ and $I_{c}$ at $77 \mathrm{~K}, 0 \mathrm{~T}$ measured to be 270,000 $\mathrm{A} / \mathrm{cm}^{2}$ and $16.7 \mathrm{~A}$, respectively.

\section{ACKNOWLEDGMENT}

The authors would like to thank P. H. Fleming for assistance in substrate preparation and film patterning.

\section{REFERENCES}

[1]. D.P. Norton, A. Goyal, J.D. Budai, D.K. Christen, D.M. Kroeger, E.D. Specht, Q. He, B. Saffian, M. Paranthaman, C.E. Klabunde, D.F. Lee, B.C. Sales, F.A. List, "Epitaxial $\mathrm{YBa}_{2} \mathrm{Cu}_{3} \mathrm{O}_{x}$ on biaxially textured nickel $(001)$ : An approach to superconducting tapes with high critical current density," Science, vol. 274, 755-757, 1996

[2]. A. Goyal, D.P. Norton, J.D. Budai, M. Paranthaman, E.D. Specht, D.M. Kroeger, D.K. Christen, Q. He, B. Saffian, F.A. List, D.F. Lee P.M. Martin, C.E. Klabunde, E. Hatfield, and V.K. Sikka, "High critical current density superconducting tapes by epitaxial deposition 
of $\mathrm{YBa}_{2} \mathrm{Cu}_{3} \mathrm{O}_{x}$ thick films on biaxially textured metals," Appl. Phys. Lett. Vol. 69, 1795-1797, 1996.

[3]. A. Goyal, D.P. Norton, D.M. Kroeger, D.K. Christen, M. Paranthaman, E.D. Specht, J. Budai, Q. He, B. Saffian, F.A. List, D.F Lee, E. Hatfield, C.E. Klabunde, P.M. Martin, J. Mathis, and C. Park "Conductors with controlled grain boundaries: an approach to the next generation, high temperature superconducting wire," J. Mater. Res. vol. 12, 2924-2940, 1997

[4]. A. Goyal, D.P. Norton, D.K. Christen, E.D. Specht, M. Paranthaman, D.M. Kroeger, J.D. Budai, Q. He, F.A. List, R. Feenstra, H.R. Kerchner, D.F. Lee, E. Hatfield, P.M. Martin, J. Mathis, and C. Park, "Epitaxial superconductors on rolling-assisted biaxially-textured substrates (RABiTS): a route towards high critical current density wire," Appl. Supercond., vol. 4, pp. 403-427, 1998.

[5]. Y.J. Tian, S. Linzen, F. Schmidl, R. Cihar, and P. Seidel, "Large area YBCO films for device fabrication," Supercond. Sci. Technol., vol. 11 , pp. 59-62, 1998.

[6]. B. Schey, W. Biegel, M. Kuhn, R. Klarmann, and B. Stritzker, "Pulsed laser deposition of YBCO thin films on $7 \times 20-\mathrm{cm}^{2}$ substrates," Appl. Surf. Sci., vol. 127-129, pp. 540-543, 1998.

[7]. B. Schey, T. Bollmeier, M. Kuhn, W. Biegel, and B. Stritzker, "Large area deposition of $\mathrm{YBa}_{2} \mathrm{Cu}_{3} \mathrm{O}_{\mathrm{x}-7}$ films by pulsed laser ablation," $\mathrm{Rev}$. Sci. Instrum., vol. 69 , pp. $474-476,1998$.

[8]. R.C.Y. Auyeung, J.S. Horwitz, L.A. Knauss, and D.B. Chrisey, "In situ pulsed laser deposition of large-area ceramic and multilayer films for applications in industry," Rev. Sci. Instrum., vol. 68, pp. 3872 $3876,1997$.

[9]. M. Lorenz, H. Hochmuth, D. Natusch, H. Borner, T. Tharigen, D.G. Patrikarakos, J. Frey, K. Kreher, S. Senz, G. Kastner, D. Hesse, M.
Steins, and W. Schmitz, "Large area and double-sided pulsed laser deposition of $\mathrm{Y}-\mathrm{Ba}-\mathrm{Cu}-\mathrm{O}$ thin films applied to HTSC microwave devices," IEEE Transact. Appl. Supercond., vol. 7, pp. 1240-1243, 1997.

[10]. M. Lorenz, H. Hochmuth, D. Natusch, H. Borner, G. Lippold, K Kreher, and W. Schmitz, "Large area double-sided pulsed laser deposition of $\mathrm{YBa}_{2} \mathrm{Cu}_{3} \mathrm{O}_{x-7}$ thin films on 3-in. sapphire wafers," Appl. Phys. Lett.., vol. 68, pp. 3332-3334, 1996.

[11]. T. Nagaishi and $\mathrm{H}$. Itozaki, "YBa $\mathrm{Cu}_{3} \mathrm{O}_{x .7}$ thin films over 3 in substrate using off-axis excimer laser deposition," J. Vac. Sci. Technol., vol. A14, pp. 1995-1998, 1996.

[12]. J.A. Greer, and M.D. Tabat, "Large area pulsed laser deposition: techniques and applications," J. Vac. Sci. Technol, vol. A13, pp. $1175-1181,1995$.

[13]. L. Correra, and S. Nicoleti, "Large-area deposition of thin films by UV pulsed laser ablation," Materials Science and Engineering B, vol. B32, pp. 33-38, 1995.

[14]. W.D. Song, C.W. An, D.S. Lu, Y.C. Fan, and Z.G. Li, "Deposition of large area $\mathrm{YBa}_{2} \mathrm{Cu}_{3} \mathrm{O}_{x \cdot 7}$ superconducting films by laser scanning ablation," Appl. Phys. Lett.., vol. 63, pp. 3370-3372, 1993.

[15]. J.A. Greer, "High quality YBCO films grown over large areas by pulsed laser deposition," J. Vac. Sci. Technol., vol. Al0, pp. 1821 $1826,1992$.

[16]. S.R. Foltyn, R.E. Muenchausen, R.C. Dye, X.D. Wu, L. Luo, D.W. Cooke, and R.C. Taber, "Large area, two-sided superconducting $\mathrm{YBa}_{2} \mathrm{Cu}_{3} \mathrm{O}_{\mathrm{x} .7}$ films deposited by pulsed laser deposition," Appl. Phys. Lett., vol. 59, pp. 1374-1376, 1991. 